\title{
Poor Metabolic Control, Hypertension and Microangiopathy Independently Increase the Transcapillary Escape Rate of Albumin in Diabetes
}

\author{
J. A. O'Hare', J. B. Ferriss', B. Twomey² and D. J. O'Sullivan ${ }^{1}$ \\ Departments of ${ }^{1}$ Medicine and ${ }^{2}$ Medical Physics, Regional Hospital and University College, Cork, Ireland
}

\begin{abstract}
Summary. Available evidence indicates that poor metabolic control and raised blood pressure each accelerate the development of diabetic microangiopathy. Microangiopathy is associated with excess albumin deposition in capillary basement membranes and it has been suggested that increased extravasation of plasma constituents may lead to basement membrane thickening. We measured the transcapillary escape rate of albumin, an indicator of the rate of extravasation of intravascular albumin from the circulation per unit time, following intravenous injection of ${ }^{125}$ I-human serum albumin. We examined the independent effects on the transcapillary escape rate of albumin of non-ketotic poor metabolic control, hypertension and microangiopathy. We studied non-diabetic control subjects and diabetic patients, initially when in non-ketotic poor metabolic control and again when control had been improved. We also studied normotensive well-controlled diabetic patients without microangiopathy, normotensive wellcontrolled diabetic patients with microangiopathy, hypertensive well-controlled diabetic patients without microangiopathy and hypertensive well-controlled diabetic patients with microangiopathy. The transcapillary escape rate of albumin
\end{abstract}

was similar in non-diabetic control subjects $(5.5 \pm 0.7 \% / \mathrm{h})$ and in both Type $1(5.3 \pm 1.2 \% / \mathrm{h})$ and Type $2(5.1 \pm 0.6 \% / \mathrm{h})$ normotensive diabetic patients without long-term complications. During poor metabolic control the transcapillary escape rate of albumin was significantly higher than in non-diabetic subjects $(8.8 \pm 0.8 \% / \mathrm{h}$ and $5.5 \pm 0.7 \% / \mathrm{h}$ respectively, $p<$ $0.01)$. With improved control values fell significantly to $6.3 \pm$ $0.9 \% / \mathrm{h}(p<0.02)$, not significantly different from control subjects. When compared with normotensive diabetic patients free of complications $(5.2 \pm 0.6 \% / \mathrm{h})$, the transcapillary escape rate of albumin was elevated in hypertensive diabetic patients without microangiopathy $(8.6 \pm 1.3 \% / \mathrm{h}, p<0.01)$, in hypertensive diabetic patients with microangiopathy $(9.2 \pm 1.2 \% / \mathrm{h}$, $p<0.005$ ), and in normotensive diabetic patients with microangiopathy $(8.1 \pm 0.9 \% / \mathrm{h}, p<0.02)$. We conclude that the transcapillary escape rate of albumin is independently elevated by poor metabolic control, by hypertension and by microangiopathy.

Key words: Diabetes mellitus, capillary permeability, plasma volume, hypertension, microangiopathy, metabolic control.
There is increasing evidence that poor metabolic control plays an important role in the development of diabetic microangiopathy [1]. Hypertension may also accelerate the development of retinopathy [2] and nephropathy [3, 4]. Capillary basement membrane thickening is an early sign of diabetic microangiopathy [5] and is associated with excess albumin deposition [6, 7]. Increased permeability to small molecules [8] and to albumin $[9,10]$ has been reported in the microcirculation of diabetic patients. It has been hypothesised that excess extravasation of plasma constituents could interfere with normal basement membrane degradation and lead to progressive thickening $[11,12]$.

The transcapillary escape rate of albumin (TER-albumin) is a measure of the fraction of the intravascular mass of albumin that passes into the extravascular space per unit time [13]. We investigated whether poor metabolic control, raised blood pressure and the presence of microangiopathy independently affect TERalbumin in diabetic patients.

\section{Subjects and Methods}

\section{Subjects}

Control subjects and diabetic patients without complications: We compared TER-albumin in non-diabetic control subjects and in normotensive diabetic patients (blood pressure consistently $<140 /$ $90 \mathrm{mmHg}$ ), who were free of long-term diabetic complications. Diabetic patients were classified according to the proposals of the National Diabetes Data Group [14]. Patients were considered free of clinically apparent complications if they had no retinopathy (assessed by direct ophthalmoscopy through dilated pupils), no symptoms and 
signs of peripheral neuropathy, no autonomic neuropathy (assessed by the pulse rate response to a maximum deep breathing and by the postural change in blood pressure), and no significant proteinuria (urinary protein $<0.18 \mathrm{~g} / 24 \mathrm{~h}$ : normal range $<0.2 \mathrm{~g} / 24 \mathrm{~h}, n=38$ ). Patients were asymptomatic, had minimal glycosuria and no ketonuria. Further patient details are given in Table 1.

Controls were normotensive non-diabetic subjects with a negative past and family history of diabetes. They were ambulatory in-patients either admitted for minor surgical procedures or recovered from short-term illness not involving the cardiovascular, renal or hepatic systems. All had normal plasma urea, creatinine, proteins, sodium, potassium and calcium and normal liver function tests.

Diabetic patients during poor and improved metabolic control: We examined eight non-ketotic normotensive diabetic patients (six males), whose mean age was 41 years (range 27-64 years) and whose mean duration of diabetes was 5 years (range 1 month-19 years). Six had Type 2 (non-insulin-dependent) and two had Type 1 (insulin-dependent) diabetes. Six were free of clinical evidence of long-term diabetic complications, while two had background retinopathy. None had proteinuria, cardiac failure or peripheral vascular disease and none was receiving medication other than for the control of diabetes. Patients were studied on two occasions; firstly when each had polydipsia, polyuria and heavy glycosuria but was free of ketonuria. Following the initial study, control was improved by dietary reinforcement in all, by the introduction of glibenclamide (three subjects), by the introduction of insulin (two subjects) and by an increase of insulin dosage (three subjects). Patients were then discharged from hospital and admitted for re-study an average of 3 weeks later (range 2-6 weeks). On the second occasion patients were asymptomatic and had minimal or no glycosuria.

Diabetic patients with complications and or hypertension: Three additional groups of diabetic patients were studied: (1) normotensive diabetic patients with retinopathy and other long-term complications $(n=12)$; (2) hypertensive diabetic patients (blood pressure $>150 / 90 \mathrm{mmHg}$ as outpatients on two or more occasions) free of clinically apparent specific complications ( $n=11)$, and (3) hypertensive patients with specific long-term diabetic complications $(n=9)$ (Table 1). Hypertension was untreated in all. None had thirst, polyuria or ketonuria. None was in cardiac failure or had symptomatic peripheral vascular disease. Some Type 2 diabetic patients (Table 1) were treated with insulin after the failure of dietary reinforcement and oral hypoglycaemic drugs to control hyperglycaemia [14].

\section{Protocol}

All subjects were studied as hospital in-patients. Diabetic control was assessed by measurement of blood glucose at $0800 \mathrm{~h}$ (fasting), 1030, 1530,2030 and $2300 \mathrm{~h}$, and by glycosylated haemoglobin measurement. Patients were studied while supine after overnight rest, $2 \mathrm{~h}$ after a light carbohydrate breakfast and their usual diabetic treatment. No patient had clinical evidence of hypoglycaemia or a blood glucose $<4 \mathrm{mmol} / 1$ during the procedures. Prior to TER-albumin measurement, blood pressure was recorded on five occasions over $15 \mathrm{~min}$ and the average of these readings was calculated. A London School of Hygiene sphygmomanometer was used to minimise observer bias. Informed consent was obtained from all subjects and the study was approved by the hospital Ethics Committee.

\section{Methods}

TER-albumin was measured by the method of Parving and Gyntelberg, who have also discussed its theoretical basis [13]. Briefly, a cannula was inserted into an ante-cubital vein and $4-8 \mu \mathrm{Ci}$ of ${ }^{125} \mathrm{I}$ labelled human serum albumin ( ${ }^{125}$ I-HSA, Amersham International, Amersham, UK) was injected, the cannula then being flushed with $5 \mathrm{ml} \mathrm{sa-}$ line $(154 \mathrm{mmol} / \mathrm{l})$. Blood was drawn, without venous occlusion, through a cannula with a three-way stop in the opposite arm, at 10,20, $30,40,50$ and $60 \mathrm{~min}$ after the injection. The cannula was maintained patent with a heparin-saline solution. The first $2 \mathrm{ml}$ from each sample was discarded to avoid contamination with blood from the previous sample. Plasma $(3 \mathrm{ml})$ was used for radioactivity counting to 10,000 counts in triplicate using a 'well' type scintillation counter (Nuclear Enterprises, Reading, UK). Background correction was made for subjects who had previous TER-albumin measurements. Using a Hewlett Packard desk computer (HP 9815 A, Palo Alto, California, USA), a linear regression equation was derived from log radioactivity against time. From the slope of this equation the TER-albumin was derived and expressed as percentage per hour [13]. Intra-assay coefficient of variation for TER-albumin was $8.6 \%$. Frequently repeated measurements of TER-albumin on the same subject were not ethically justifiable because of the radiation exposure involved. However three measurements in the same subject over an eight-month period gave a coefficient of variation of $11.2 \%$. Plasma volume was calculated by extrapolation to zero time for radioactivity from the regression equation, and the exact volume of ${ }^{125}$ I-HSA injected was calculated by weighing the syringe before and after injection. Plasma volume was calculated by a standard method and expressed in relation to body surface area [15].

Plasma albumin, urea, creatinine and bicarbonate were measured by an autoanalyser (SMAC, Technicon, Tarrytown, NY, USA), blood glucose by the glucose oxidase method and $\mathrm{HbA}_{1}$ by ion exchange chromatography (Bio-Rad Laboratories, Richmond, California; normal range $4.9 \%-8 \%)$. Urinary albumin was measured by a colorimetric method [16] using HSA as standard.

Results are expressed as mean \pm SEM. Statistical analysis is by paired and unpaired Student's t-tests as appropriate, and by Pearson's correlation coefficient.

\section{Results}

\section{Comparison of Non-diabetic Subjects and Diabetic Patients Without Complications}

Control subjects and diabetic patients without complications were of similar age, body weight and had similar blood pressure levels. In the diabetic patients, 24-h urinary albumin excretion was similar to that of an expanded control group of 38 normal subjects. TER-albumin, plasma volume and plasma albumin concentration were similar in control and diabetic subjects (Table 1 ). TER-albumin was similar in five Type 1 and seven Type 2 diabetic patients $(5.3 \pm 1.2$ and $5.1 \pm 0.6 \% / \mathrm{h}$, respectively).

\section{Effect of Improved Metabolic Control (Table 2)}

TER-albumin during poor metabolic control was $8.8 \pm$ $0.8 \% / \mathrm{h}$, which was higher than in non-diabetic control subjects, in whom TER-albumin was $5.5 \pm 0.7 \% / \mathrm{h}(p<$ 0.01 ). With improved control TER-albumin fell significantly to $6.3 \pm 0.9 \% / \mathrm{h}(p<0.02)$, a level comparable to the non-diabetic subjects. Plasma albumin rose when control improved, from $34.1 \pm 1.6 \mathrm{~g} / \mathrm{l}$ to $36.1 \pm 2.1 \mathrm{~g} / 1$ $(p<0.05)$.

\section{Comparison of Normotensive and Hypertensive Diabetic Patients Without Complications (Table 1)}

Mean blood glucose, $\mathrm{HbA}_{1}$, 24-h urine albumin excretion and creatinine clearance were similar in these two groups, although the hypertensive diabetic patients were significantly older and more obese. All hypertensive patients had Type 2 diabetes. TER-albumin was significantly higher in hypertensive $(8.6 \pm 1.3 \% / \mathrm{h})$ than 
Table 1. Comparisons between non-diabetic control subjects and diabetic patients with and without long-term complications

\begin{tabular}{|c|c|c|c|c|c|c|c|c|c|}
\hline & \multirow{2}{*}{\multicolumn{2}{|c|}{$\begin{array}{l}\text { Control } \\
\text { (non-diabetic) } \\
\text { subjects } \\
(n=12)\end{array}$}} & \multicolumn{4}{|c|}{ Diabetic patients without complications } & \multicolumn{3}{|c|}{ Diabetic patients with complications } \\
\hline & & & \multicolumn{2}{|c|}{$\begin{array}{l}\text { Normotensive } \\
(n=12)\end{array}$} & \multicolumn{2}{|c|}{$\begin{array}{l}\text { Hypertensive } \\
(n=11)\end{array}$} & \multicolumn{2}{|c|}{$\begin{array}{l}\text { Normotensive } \\
(n=12)\end{array}$} & $\begin{array}{l}\text { Hypertensive } \\
(n=9)\end{array}$ \\
\hline Sex ratio $(M: F)$ & $11: 1$ & & $9: 3$ & & $3: 8$ & & $11: 1$ & & $7: 2$ \\
\hline Age (years) & 44.3 & \pm 4.2 & 44.5 & \pm 5.1 & 63.7 & $\pm 2.4^{\mathrm{c}}$ & 55.9 & \pm 4.5 & $51.2 \pm 4.6$ \\
\hline Duration of diabetes (years) & - & & 4.8 & \pm 2.0 & 5.6 & \pm 1.6 & 10.9 & $\pm 2.1^{\mathrm{a}}$ & $13.6 \pm 3.6^{\mathrm{a}}$ \\
\hline Type of diabetes (Type 1 /Type 2) & - & & $5 / 7$ & & $0 / 11$ & & $3 / 9$ & & $3 / 6$ \\
\hline $\begin{array}{l}\text { Treatment: insulin/oral } \\
\text { hypoglycaemics }\end{array}$ & - & & $7 / 5$ & & $2 / 9$ & & $8 / 4$ & & $5 / 4$ \\
\hline $\begin{array}{l}\text { Retinopathy: } \\
\text { background/proliferative }\end{array}$ & - & & nil & & nil & & $10 / 2$ & & $5 / 3$ \\
\hline Neuropathy:peripheral/autonomic & - & & nil & & nil & & $9 / 6$ & & $8 / 3$ \\
\hline $\begin{array}{c}\text { Nephropathy }(>0.5 \mathrm{~g} \\
\text { proteinuria/ } 24 \mathrm{~h})\end{array}$ & - & & nil & & nil & & 3 & & 9 \\
\hline Mean blood glucose (mmol/1) & 5.7 & \pm 0.2 & 8.7 & \pm 0.5 & 8.0 & \pm 0.6 & 9.3 & \pm 0.7 & $9.7 \pm 0.9$ \\
\hline $\mathrm{HbA}_{1}(\%)$ & - & & 9.3 & \pm 0.2 & 8.5 & \pm 0.7 & 9.6 & \pm 0.5 & $9.7 \pm 0.8$ \\
\hline Mean arterial pressure $(\mathrm{mmHg})$ & 86.3 & \pm 2.0 & 87.2 & \pm 2.8 & 115.2 & $\pm 4.3^{\mathrm{e}}$ & 89.8 & \pm 2.0 & $124.0 \pm 6.0^{\circ}$ \\
\hline Plasma urea $(\mathrm{mmol} / \mathrm{l})$ & 4.8 & \pm 0.2 & 5.4 & \pm 0.3 & 6.3 & \pm 0.6 & 5.5 & \pm 0.4 & $9.6 \pm 2.3^{\mathrm{a}}$ \\
\hline Creatinine clearance $(\mathrm{ml} / \mathrm{min})$ & - & & 88.4 & \pm 8.7 & 71.5 & \pm 6.4 & 93.4 & \pm 9.5 & $55.1 \pm 14.0^{\mathrm{a}}$ \\
\hline Urinary albumin excretion $(\mathrm{g} / 24 \mathrm{~h})$ & 0.08 & \pm 0.01 & 0.09 & \pm 0.02 & 0.09 & \pm 0.02 & 0.29 & $\pm 0.06^{\mathrm{c}}$ & $1.52 \pm 0.39^{\mathrm{a}}$ \\
\hline$\%$ ideal body weight & 95.4 & \pm 5.0 & 103.2 & \pm 4.0 & 123.6 & $\pm 6.1^{\mathrm{c}}$ & 97.1 & \pm 4.1 & $107.7 \pm 4.4$ \\
\hline $\begin{array}{l}\text { Transcapillary escape rate of } \\
\text { albumin }(\% / \mathrm{h})\end{array}$ & 5.5 & \pm 0.7 & 5.2 & \pm 0.6 & 8.6 & $\pm 1.3^{\mathrm{c}}$ & 8.1 & $\pm 0.9^{\mathrm{b}}$ & $9.2 \pm 1.2^{\mathrm{d}}$ \\
\hline Plasma albumin $(\mathrm{g} / 1)$ & 36.0 & \pm 0.9 & 36.2 & \pm 1.6 & 37.0 & \pm 0.8 & 35.9 & \pm 1.0 & $34.7 \pm 0.9$ \\
\hline Plasma volume $\left(1 / 1.73 \mathrm{~m}^{2}\right)$ & 3.002 & \pm 0.141 & 3.111 & \pm 0.129 & 2.68 & $4 \pm 0.151^{\mathrm{a}}$ & 2.78 & $\pm 0.090^{\mathrm{a}}$ & $2.878 \pm 0.249$ \\
\hline
\end{tabular}

Results expressed as mean \pm SEM.

Statistical comparisons in each case are with normotensive diabetic patients without complications. $p:^{\mathrm{a}}<0.05 ;^{\mathrm{b}}<0.02 ;^{\mathrm{c}}<0.01 ;{ }^{\mathrm{d}}<0.005 ;^{\mathrm{e}}<0.001$

Table 2. Effect of poor and subsequently improved metabolic control on TER-albumin

\begin{tabular}{|c|c|c|c|c|c|}
\hline \multirow[b]{2}{*}{$\begin{array}{l}24 \mathrm{~h} \text { mean blood } \\
\text { glucose }(\mathrm{mmol} / \mathrm{l})\end{array}$} & \multicolumn{2}{|c|}{ 'Poor control' } & \multicolumn{2}{|c|}{$\begin{array}{l}\text { 'Improved } \\
\text { control' }\end{array}$} & \multirow{2}{*}{$\begin{array}{l}p \\
<0.001\end{array}$} \\
\hline & 16.0 & \pm 1.0 & 7.8 & \pm 1.2 & \\
\hline $\mathrm{HbA}_{1}(\%)$ & 11.9 & \pm 0.6 & 9.6 & \pm 0.3 & $<0.001$ \\
\hline $\begin{array}{l}\text { Venous bicarbonate } \\
(\mathrm{mmol} / \mathrm{l})\end{array}$ & 24.7 & \pm 1.5 & 25.4 & \pm 1.7 & NS \\
\hline $\begin{array}{l}\text { Blood pressure } \\
(\mathrm{mmHg}): \text { Systolic }\end{array}$ & 124.0 & \pm 7.0 & 122.0 & \pm 6.7 & NS \\
\hline Diastolic & 73.5 & \pm 2.5 & 68.3 & \pm 2.7 & $<0.05$ \\
\hline Mean & 89.8 & \pm 3.7 & 86.2 & \pm 1.0 & NS \\
\hline $\begin{array}{l}\text { Transcapillary escape } \\
\text { rate of albumin }(\% / h)\end{array}$ & 8.8 & \pm 0.8 & 6.3 & \pm 0.9 & $<0.02$ \\
\hline Plasma albumin $(\mathrm{g} / 1)$ & 34.1 & \pm 1.6 & 36.1 & \pm 2.1 & $<0.05$ \\
\hline Plasma volume (l) & 3.02 & \pm 0.253 & 3.1 & $1 \pm 0.226$ & NS \\
\hline
\end{tabular}

Results expressed as mean \pm SEM of eight observations. Statistical analysis by paired $t$-test. $\mathrm{NS}=$ not significant

in the combined normotensive diabetic patients $(5.2 \pm$ $0.6 \% \mathrm{~h}, p<0.01$ ) or in normotensive Type 2 diabetic patients alone $(5.1 \pm 0.6 \% / \mathrm{h}, p<0.01)$. Plasma volume was lower in hypertensive diabetic patients $(p<0.05)$.

\section{Comparison of Diabetic Patients With and Without Long-Term Complications (Table 1)}

Diabetic patients with complications were subdivided into those without and those with hypertension. Metabolic control was comparable in these two groups and was also similar to diabetics without complications.
Both diabetic groups with complications had significantly longer duration of diabetes and significantly higher urine albumin excretion than diabetics free of complications. TER-albumin was higher both in the normotensive group $(8.1 \pm 0.9 \% / \mathrm{h}, p<0.02)$ and in the hypertensive group with complications $(9.2 \pm 1.2 \% / \mathrm{h}$, $p<0.005)$, compared with normotensive diabetic patients without long-term complications $(5.2 \pm 0.6 \% / \mathrm{h})$.

\section{Relationships Between TER-Albumin and Other Variables}

TER-albumin was not significantly related to age, percentage ideal body weight or to creatinine clearance in either control or diabetic subjects. TER-albumin also failed to relate to the duration of diabetes, mean blood glucose or $\mathrm{HbA}_{1}$ levels. It did however correlate significantly with systolic, diastolic and mean arterial pressures in diabetic patients ( $r=0.38, p<0.01$ for each). TER-albumin was inversely related to plasma volume in both control $(r=-0.59, p<0.05)$ and diabetic subjects $(r=-0.50, p<0.001)$. It also correlated with $\log$ 24-h urinary albumin excretion $(r=0.38, p<0.01)$ in the diabetic patients as a group.

\section{Discussion}

TER-albumin was normal in normotensive diabetic patients free of long-term complications and was similar in Type 1 and Type 2 patients. Elevated TER-albumin has previously been demonstrated in diabetic patients with 
ketoacidosis [9]. We have extended these observations by demonstrating a reversibly elevated TER-albumin in poorly-controlled diabetics who were not acidotic. Our findings suggest that elevated TER-albumin in diabetes is a consequence of the diabetic state and its complications, rather than a phenomenon preceding or linked to the development of diabetes.

Elevated TER-albumin in hypertensive diabetic patients occurred independently of diabetic control or diabetic complications, consistent with a report that hypertension in non-diabetic subjects is associated with elevated TER-albumin [13]. As neither age nor obesity were related to TER-albumin in control or diabetic subjects, it is unlikely that these variables influenced TERalbumin in the hypertensive diabetic patients free of complications. Our observation of an inverse relationship between TER-albumin and plasma volume corroborates Ulrych's observation [17], but contrasts with those of Parving and Gyntelberg [13]. The reason for these differences is unclear. The reduced plasma volume in hypertensive patients [17] and the elevated TERalbumin may each be a consequence of elevated postcapillary resistance, which increases albumin and fluid filtration at the capillary wall [18].

The elevated TER-albumin in diabetic patients with complications is in agreement with a previous report [10]. In the present study we demonstrated that it occurs independently of poor metabolic control and hypertension. Complications and hypertension together did not appear to have an additive effect, perhaps because there is a ceiling for the maximum rate of escape of albumin from the circulation. Increased urinary protein excretion in diabetics with complications is not the cause of elevated TER-albumin, as less than $1 \%$ of the intravascular mass of albumin appears in the urine over a onehour period. Possible mechanisms by which TER-albumin is elevated in diabetic patients with complications have been discussed elsewhere $[9,10]$. Important factors in the presence of microangiopathy may be abnormal capillary endothelial pores [8] and alterations in microvascular blood flow, especially when neuropathy is present [19] as was the case in many of our patients.

Albumin deposition in capillary basement membrane is characteristic of diabetic microangiopathy in the kidney [6,7] and other tissues [20]. Glycosylated proteins have experimentally produced diabetic-like glomerular changes [21] and glycosylated human serum albumin [22] may contribute to diabetic microangiopathy. Increased transcapillary escape rate of albumin may be a marker for, or pathogenic in the development of basement membrane thickening. The present study demonstrates that metabolic control, hypertension and the presence of microangiopathy independently increase albumin leakage from the circulation.

Acknowledgements. This work was supported by a grant from the Medical Research Council of Ireland. We are grateful to Mr. N.Martin for $\mathrm{HbA}_{1}$ measurements, and to our colleagues in the Department of Biochemistry for blood glucose and for urinary and plasma protein measurements.

\section{References}

1. Tchobroutsky G (1978) Relation of diabetic control to development of microvascular complications. Diabetologia 15: 143-152

2. Knowler WC, Bennett PH, Ballintine EJ (1980) Increased incidence of retinopathy in diabetics with elevated blood pressure. $\mathrm{N}$ Eng J Med 302: 645-650

3. Mogensen CE (1976) Renal function changes in diabetes. Diabetes 25 (Suppl 2): 872-879

4. Mauer SM, Steffes MW, Azar S, Sandberg SK, Brown DM (1978) The effect of Goldblatt hypertension on development of the glomerular lesions of diabetes mellitus in the rat. Diabetes 27: $738-744$

5. Williamson JR, Kilo C (1977) Current status of capillary basement-membrane disease in diabetes mellitus. Diabetes 26: 65--73

6. Westberg NG, Michael AF (1972) Immunohistopathology of diabetic glomerulosclerosis. Diabetes 21: 163-174

7. Michael AF, Brown DM (1981) Increased concentration of albumin in kidney basement membranes in diabetes mellitus. Diabetes 30: $843-846$

8. Trap-Jensen J (1971) Permeability of small vessels in diabetes. Acta Diabet Lat 8 (Suppl 1): 192-200

9. Parving HH, Noer I, Deckert T, Evrin PE, Nielsen SL, Lyngsoe J, Mogensen CE, Rorth M, Svendsen P, Trap-Jensen J, Lassen NA (1976) The effect of metabolic regulation on microvascular permeability to small and large molecules in short-term juvenile diabetics. Diabetologia 12: 161-166

10. Parving HH (1976) Increased microvascular permeability to plasma proteins in short- and long-term juvenile diabetics. Diabetes 25 (Suppl 2): 884-889

11. Williamson JR, Kilo C (1976) Basement membrane thickening and diabetic microangiopathy. Diabetes 25 (Suppl 2): 925-927

12. Brownlee M (1976) $\alpha_{2}$ macroglobulin and reduced basement membrane degradation in diabetes. Lancet 1:779-780

13. Parving HH, Gyntelberg $F$ (1973) Transcapillary escape rate of albumin and plasma volume in essential hypertension. Cir Res 32: 643-651

14. National Diabetes Data Group (1979) Classification and diagnosis of diabetes mellitus and other categories of glucose intolerance. Diabetes 28: 1039-1057

15. Feldschuh J, Enson Y (1977) Prediction of the normal blood volume: Relation of blood volume to body habitus. Circulation 56 , 605-612

16. Hemmingsen L (1972) A simple and rapid method for quantitative determination of protein in urine. Clin Chim Acta 36: 185-188

17. Ulrych M (1973) Plasma volume decrease and elevated Evans Blue disappearance rate in essential hypertension. Clin Sci Mol Med 45: 173-181

18. London GM, Safar ME, Levenson JA, Simon AC, Temmar MA (1981) Renal filtration fraction, effective vascular compliance and partition of fluid volumes in sustained essential hypertension. Kidney Intern 20: 97-103

19. Boulton AJM, Scarpello JHB, Ward JD (1982) Venous oxygenation in the diabetic neuropathic foot: evidence of arteriovenous shunting? Diabetologia 22: 6-8

20. Chavers B, Etzwiler D, Michael AF (1981) Albumin deposition in dermal capillary basement membrane in insulin-dependent diabetes mellitus. Diabetes: $30: 275-278$

21. McVerry BA, Fisher C, Hopp A, Huehns ER (1980) Production of pseudodiabetic renal glomerular changes in mice after repeated injections of glucosylated proteins. Lancet $1: 738-740$

22. Kennedy L, Mehl TD, Elder E, Varghese M, Merimee TJ (1982) Non-enzymatic glycosylation of serum and plasma proteins. Diabetes 31 (Suppl 3): 52-56

Received: 9 November 1982

and in revised form: 28 June 1983

Professor J. B. Ferriss

Department of Medicine

Regional Hospital

Cork

Ireland 